\title{
Selection of Colors and Patterns for Geologic Maps of the U.S. Geological Survey
}

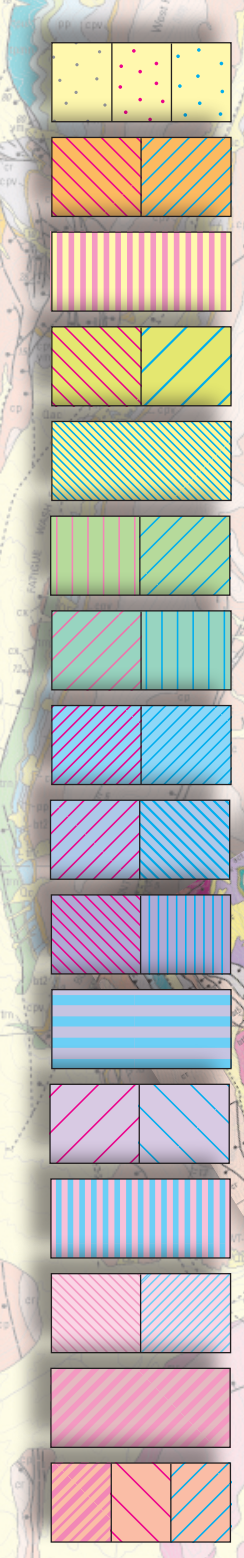

Techniques and Methods 11-B1 


\section{Selection of Colors and Patterns for Geologic Maps of the U.S. Geological Survey}

By U.S. Geological Survey

2005

Techniques and Methods 11-B1

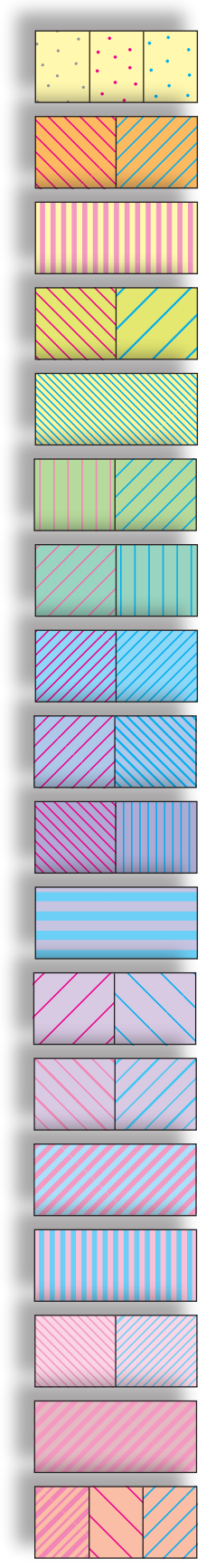

U.S. Department of the Interior

U.S. Geological Survey 


\section{U.S. Department of the Interior \\ Gale A. Norton, Secretary \\ U.S. Geological Survey \\ Charles G. Groat, Director}

U.S. Geological Survey, Reston, Virginia: 2005

Manuscript approved for publication, February 25, 2005

PDF files of this publication are available at http://cpg.cr.usgs.gov/pub/

For sale by U.S. Geological Survey Information Services

Box 25286, Federal Center, Denver, C0 80225

For product and ordering information:

World Wide Web: http://www.usgs.gov/pubprod

Telephone: 1-888-ASK-USGS

For more information on the USGS--the Federal source for science about the Earth, its natural and living resources, natural hazards, and the environment:

World Wide Web: http://www.usgs.gov

Telephone: 1-888-ASK-USGS

Any use of trade, product, or firm names in this publication is for descriptive purposes only and does not imply endorsement by the U.S. Government.

Although this report is in the public domain, permission must be secured from the individual copyright owners to reproduce any copyrighted materials contained within this report. 


\section{Contents}

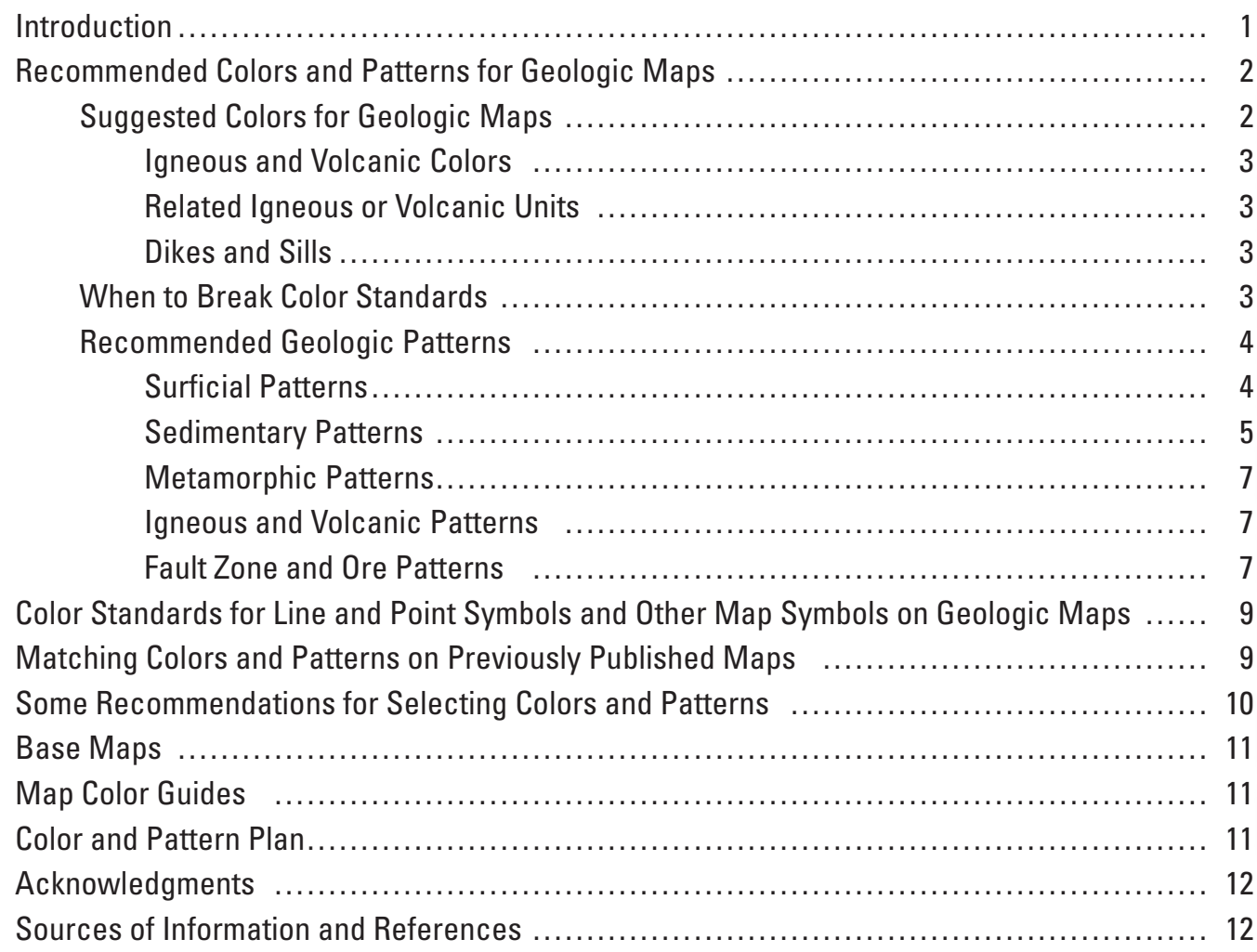

\section{Tables}

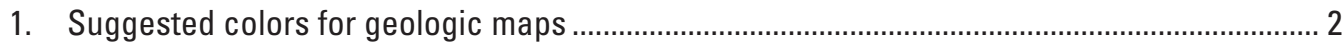

2. Suggested background colors and colors for sedimentary line and other patterns for geologic maps. .

3. Selected examples of background colors and various point patterns for geologic maps ....... 8

\section{Plate}

\{in pocket\}

1. Suggested colors for geologic maps
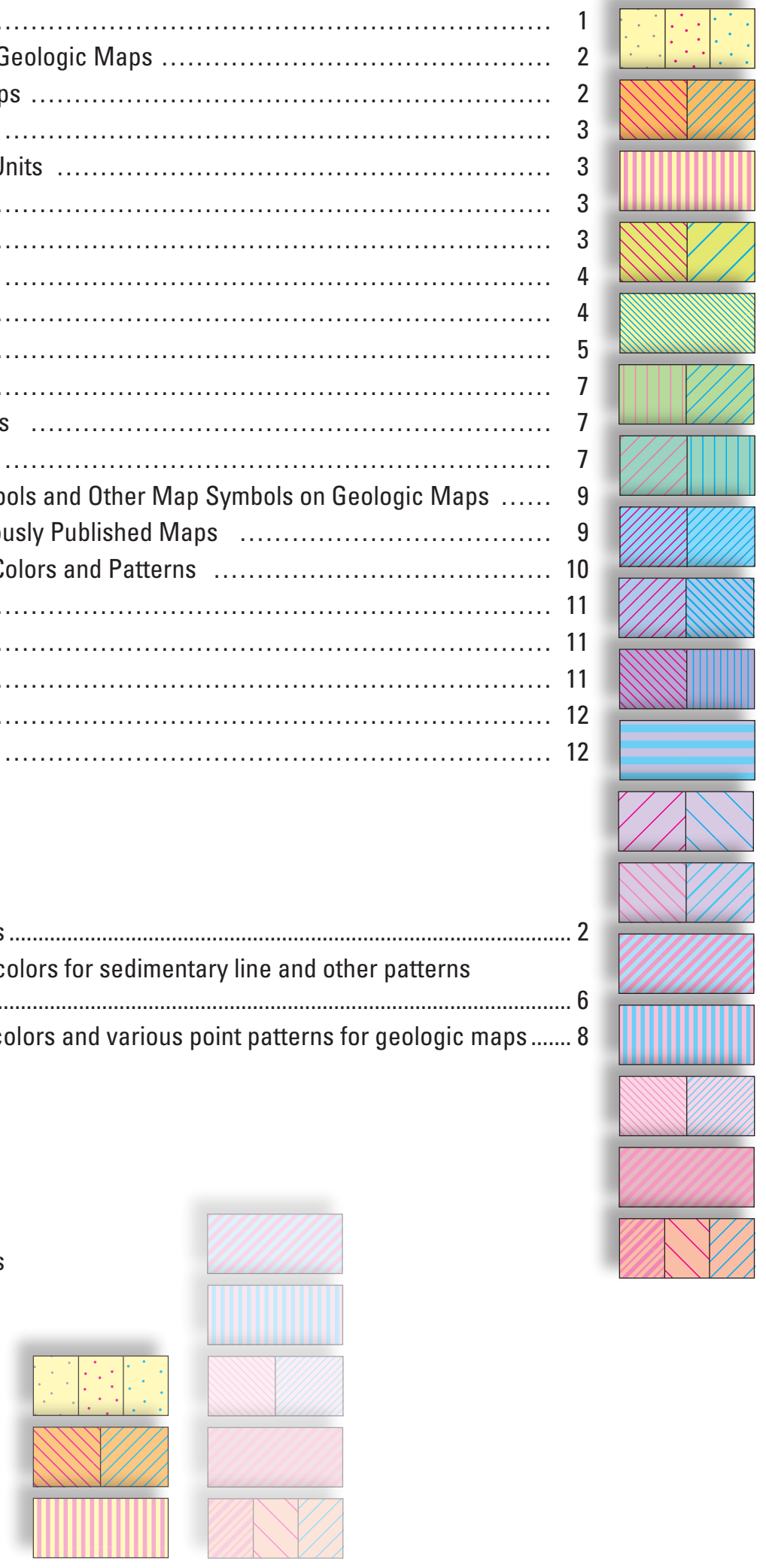


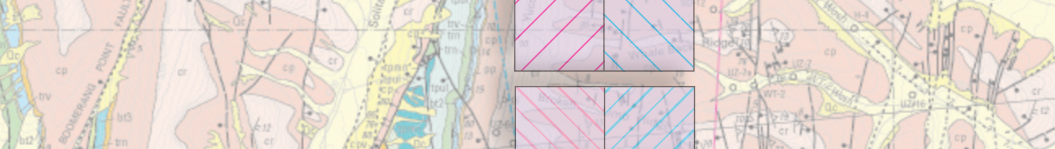

Lat. 1.

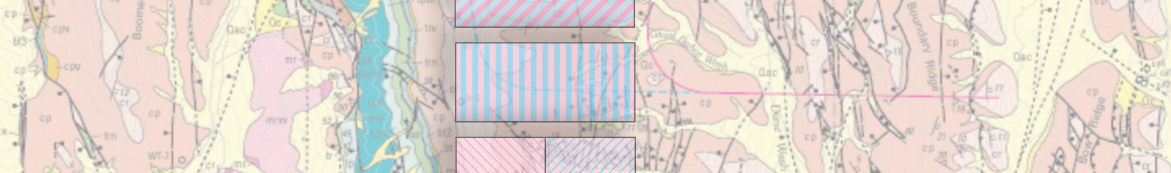

H.

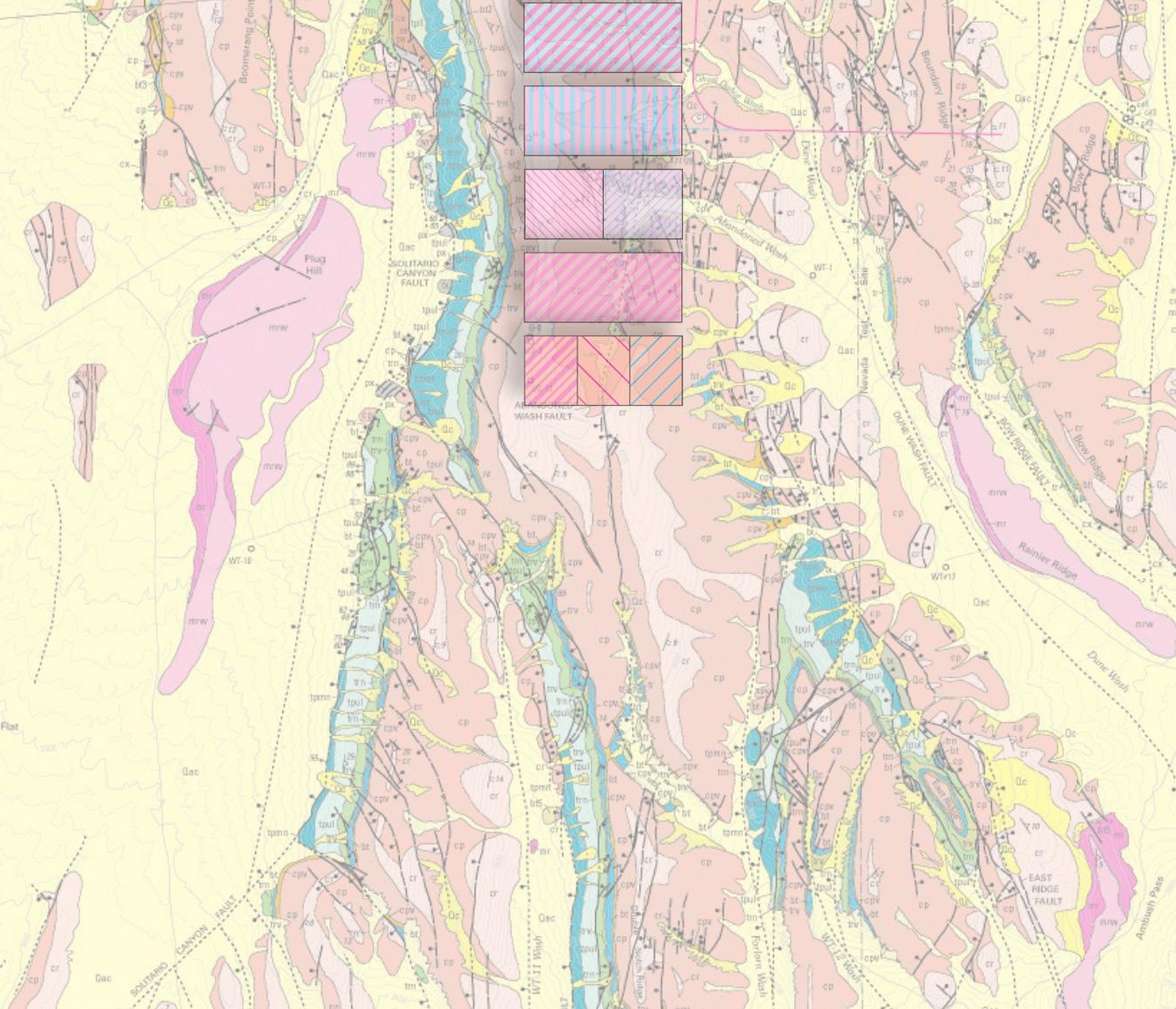

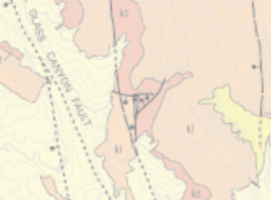

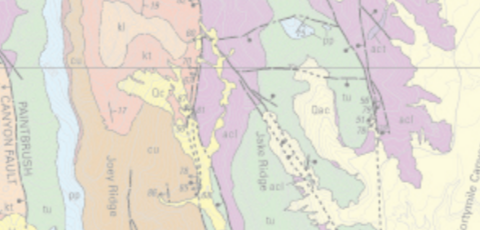
in

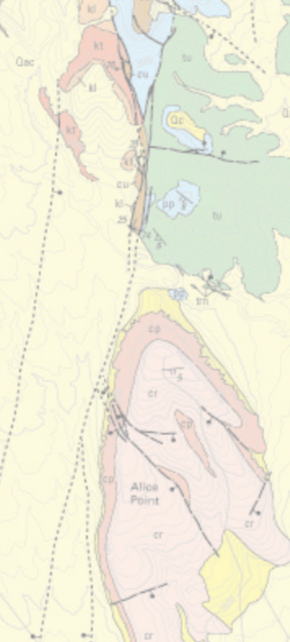

t. 


\title{
Selection of Colors and Patterns for Geologic Maps of the U.S. Geological Survey
}

\author{
By U.S. Geological Survey \\ 2005
}

\section{Introduction}

U.S. Geological Survey (USGS) color and pattern standards and conventions for geologic maps have evolved since the first set of standards was published by the USGS in 1881. Since that time, USGS personnel have continuously updated and revised the standards in response to the need to show increasingly complex geologic map data and in response to changing technology. We recommend that the standards and conventions not be ignored.

Many U.S. State geological surveys and geological surveys throughout the world have adopted the color scheme as devised by the USGS. This color scheme is also referred to as the "American color system." Shortly after 1881, the Europeans developed their own color scheme, which is referred to as the "International color system."

Color and pattern selections on USGS maps are based mainly on the following factors:

- Purpose and use of the map

- Legibility of the map

- Applying USGS color and pattern standards and conventions

- Showing contrast and clarity of map units and symbols

- Showing ages or age relationships of map units

- Matching or approximating colors and patterns used on nearby or adjacent maps to maintain consistency and continuity of colors and patterns among maps in a region

- Showing structural relationships of map units

- Cost of publication

- Using colors that are light enough for easy readability of the base map

- Emphasis of certain map units or symbols 


\section{Recommended Colors and Patterns for Geologic Maps}

[Modified and updated from USGS Publications Division Technical Standards Paper No. 9.03.1, dated September 30, 1971.]

\section{Suggested Colors for Geologic Maps}

Table 1. Suggested colors for geologic maps. CMYK values: $A=8 \%, 1=13 \%, 2=20 \%, 3=30 \%, 4=40 \%, 5=50 \%, 6=60 \%, 7=70 \%, X=100 \%$.

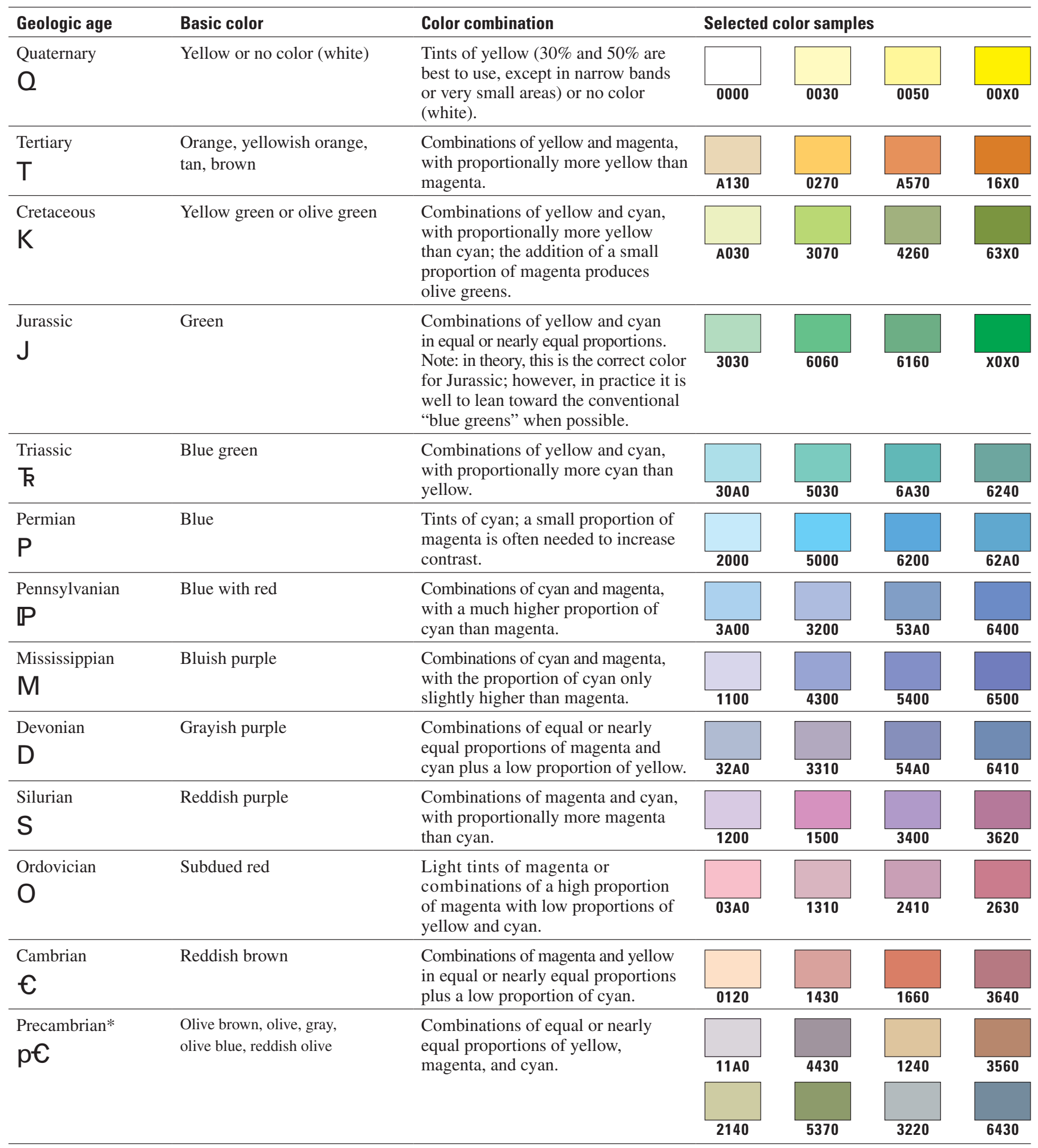

\footnotetext{
*Includes Proterozoic and Archean.
} 


\section{Igneous and Volcanic Colors}

The colors used for igneous and volcanic units should contrast strongly with adjoining sedimentary units. Reds are generally preferred; however, any strongly saturated color may be used. Large areas should be in light tints of magenta; small areas should be in the brighter tints. In other words, the smaller the area, the brighter the color.
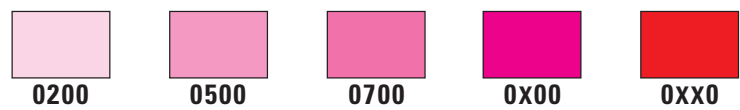

\section{Related Igneous or Volcanic Units}

A tonal sequence of a color should be used when related groups of igneous or volcanic units are shown on a map. The groups may be related by age, chemical composition, or type of igneous activity. Reds, oranges, and reddish-purples are most commonly used. Blues, greens, and purples are used when a map has several groups of igneous or volcanic units, or when these colors are needed to create contrast.

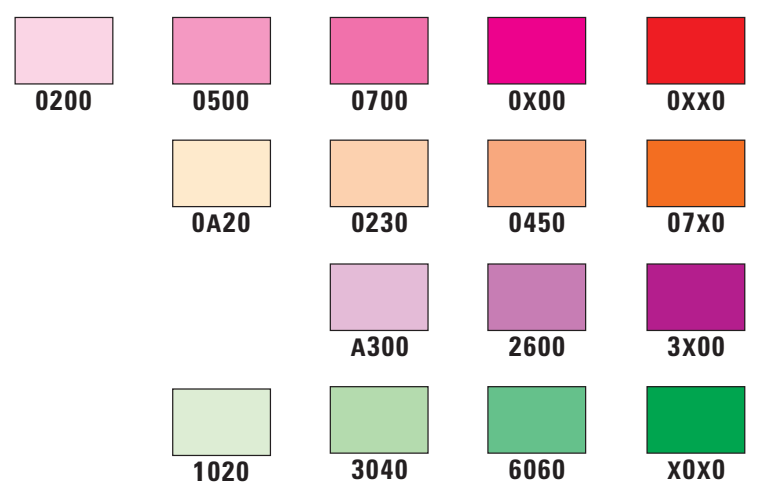

\section{Dikes and Sills}

Narrow dikes and sills that cannot be shown as polygons are shown as solid lines overprinting other geologic units and must be printed in a bright or strong color so they will be seen.

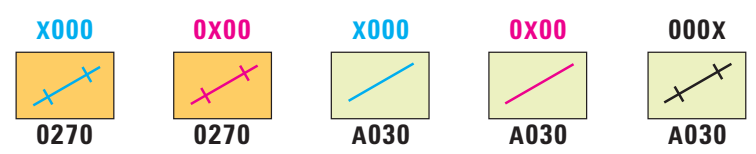

\section{When To Break Color Standards}

The age color scheme is most easily applied to geologic maps that do not have many units of any one geologic age. On large geologic maps that have many map units, it is sometimes impossible to maintain the standard geologic age colors. Some of the ways to modify the color selections for complex or otherwise challenging maps are described below.

A common problem is when there are map units of many geologic ages on the map, but one or more ages have too many units. To solve this problem, select colors that maintain the relative order of colors on the geologic age column but move up and (or) down on the column. For example, for a geologic age that has too many units, use the color immediately above the geologic age color for the youngest units, the correct color for the middle units, and the color immediately below the geologic age for the older units.

Even when breaking color standards, it is important to maintain the modified spectral order of the colors so that the map reader is able to identify the relative age of the units by color. In other words, orange areas represent units younger than those that are green, and green areas represent units younger than those that are blue.

Another situation in which color standards need to be broken is when all of the map units are of one geologic age, and there aren't enough different shades of the recommended color to show all of the different map units. An example is USGS map I-2225 (Moore, and Trusdell, 1991), which has about 120 map units, all of Quaternary age. Yellow could not be used to distinguish all 120 map units, so the entire spectrum of colors was used on this map. 


\section{Recommended Geologic Patterns}

Patterns tend to obscure the base map and should be used only when necessary. The patterns shown in the following paragraphs are those most frequently used by map designers in the USGS. These patterns and many others that are less frequently used are shown on plate B of the Digital Cartographic Standard (see http://pubs.usgs.gov/of/1999/of99-430/). The pattern numbers in the following paragraphs refer to that plate.

Patterns are used when they help to maintain the basic color scheme on complex maps; they often can effectively show relationships between units as well as imply the type of rock being represented. Patterns are most often used for surficial and for igneous and volcanic units.

\section{Surficial Patterns}

Stipple and circular patterns are used to show surficial deposits. Normally these patterns have a random arrangement of stipples and circles; however, regularly spaced patterns may be used to create contrast among units. Generally, the spacing of the patterns should correspond to the relative size and to the character of the material being represented. For example, a fine stipple pattern should be used for sand while a coarser stipple pattern with or without circles indicates a coarse gravel or conglomerate. Patterns are generally used as follows:

Sand

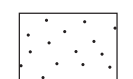

117

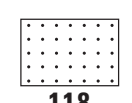

118

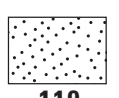

119
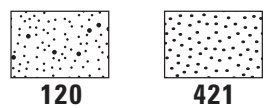

Gravel, sand and gravel
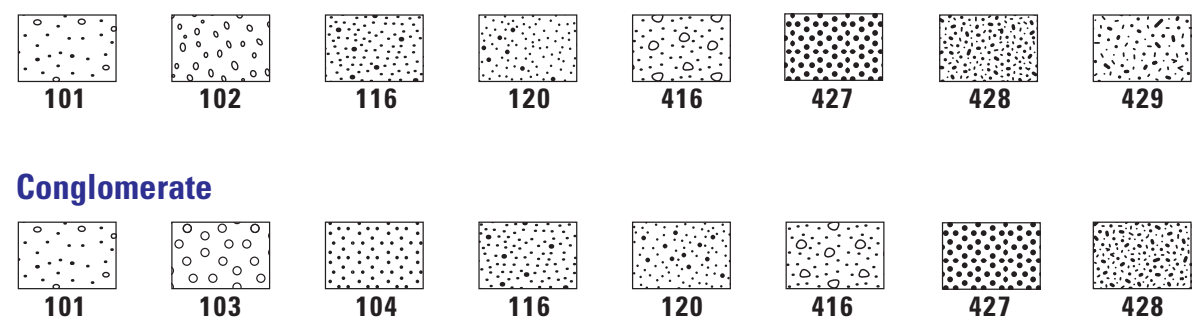

\section{Conglomerate}
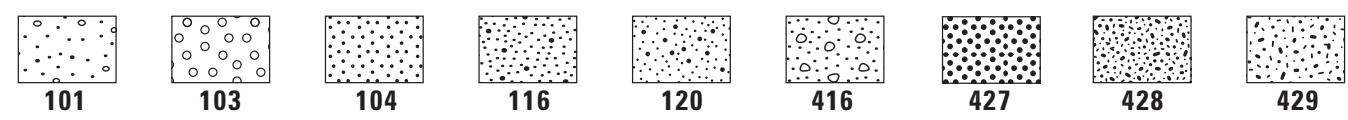

Talus, breccia, landslides
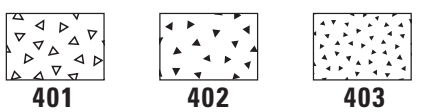

403

\section{Glacial moraine}

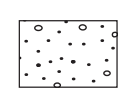

101

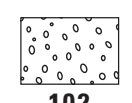

102

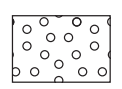

103

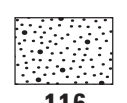

116

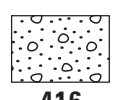

416

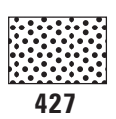

427

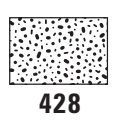

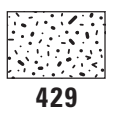

429
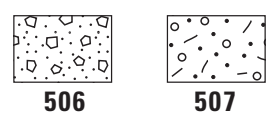

507

Since surficial deposits are usually Quaternary in age, the patterns should overprint a yellow background. If there are numerous surficial units, a yellow background is used for the younger units and a pale orange or light brown background is used for the older units. Patterns printed in cyan over a yellow background will appear green. Fine magenta patterns over a yellow background will appear red; dense magenta patterns over a yellow background will appear orange. The dots and circles can be screened to 50 percent if the background color is very light.

Patterns may be used to relate groups of units by printing a number of different patterns in one color over yellow and a second group of patterns in another color. Hence, the map reader would immediately be able to identify a surficial unit by its background color and to recognize its relationship to other units by the color used for the overprinting pattern. 


\section{Sedimentary Patterns}

Line patterns of different spacings and line widths are often used for sedimentary units on complex geologic maps. Before resorting to the use of line patterns, some USGS map designers prefer to use surficial patterns (sand, gravel, conglomerate), as needed, for sedimentary map units composed mostly of sandstone or conglomerate. Patterns with solid lines are for general use; other patterns indicate lithology; suggested examples of both are shown below.

Sedimentary units in general

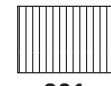

201
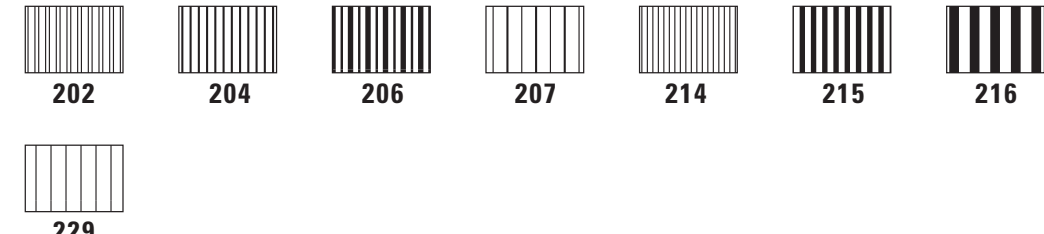

228

Shale
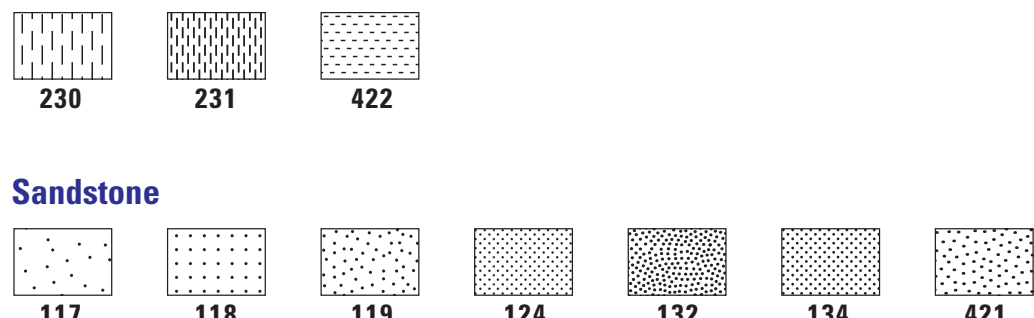

134
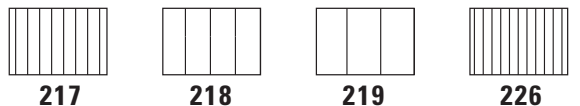

226

\section{Sandstone}

\section{Evaporites (gypsum, salt)}
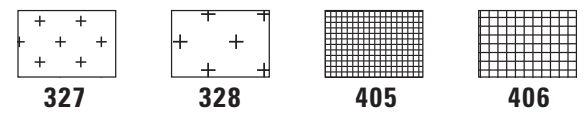

(Print patterns 405 and 406 with one set of lines horizontal)

\section{Breccia, angular conglomerate}
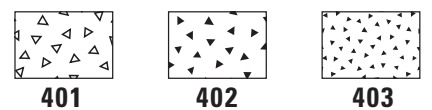

To select sedimentary patterns, choose the background color and then select the pattern, visualizing the effect that the pattern will have on the background. If the pattern is "light" (for example, either fine lines or widely spaced lines or a fine stipple pattern), the background will remain dominant when the pattern overprints it. If the pattern is "heavy" or dense, the background color will be changed because the pattern will print as a component part of the color.

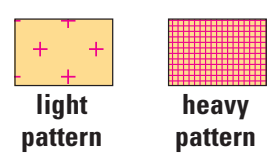

(The two examples to the left have the same background color)

Generally, line patterns for sedimentary rocks should be angled at $45^{\circ}$ or at $135^{\circ}$. Occasionally they are used horizontally or vertically, perpendicular to the long axis of a narrow map unit.

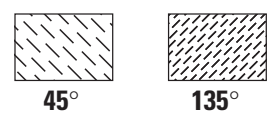


The following table summarizes the selection of suggested background colors and colors for sedimentary line and other patterns on general geologic maps. Some selected examples are shown.

Table 2. Suggested background colors and colors for sedimentary line and other patterns for geologic maps.

CMYK values: $\mathrm{A}=8 \%, 1=13 \%, 2=20 \%, 3=30 \%, 4=40 \%, 5=50 \%, 6=60 \%, 7=70 \%, \mathrm{X}=100 \%$.

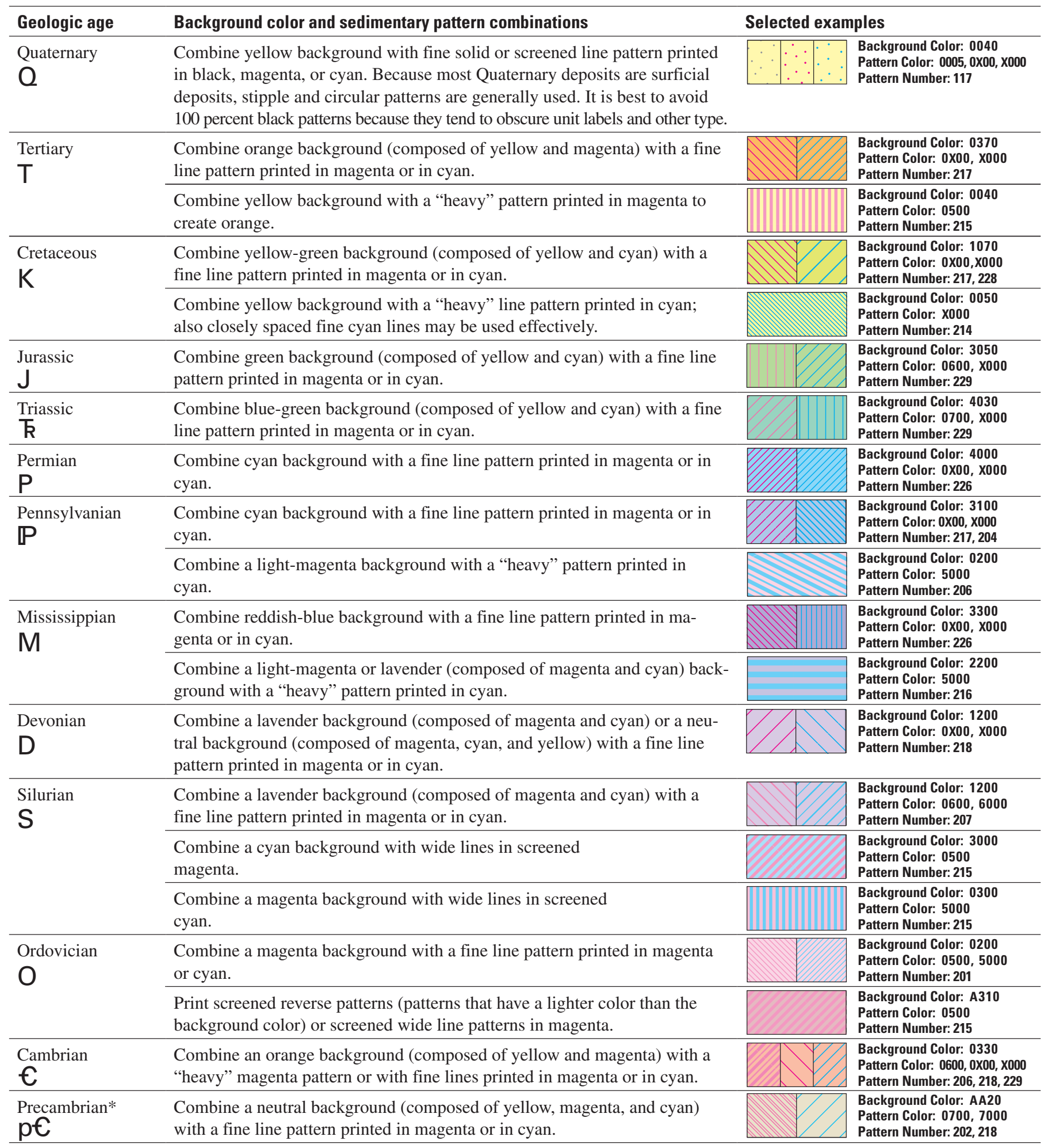

*Includes Proterozoic and Archean. 


\section{Metamorphic Patterns}

Metamorphic units are usually shown without patterns because the traditional metamorphic patterns make the base map very difficult to read. The available metamorphic patterns are used as follows:

\section{Metamorphic rocks in general}

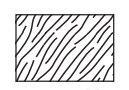

431-K

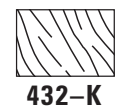

(May be used on maps which have planimetric bases)

\section{Schist}
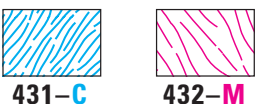

(Used only if direction of trend is known; print in cyan or magenta over the appropriate geologic age color background)

\section{Igneous and Volcanic Patterns}

Patterns for igneous and volcanic rocks are angular or geometric forms, such as hachures, v's, and +'s, which are usually printed in magenta, screened black, or cyan. The patterns are used to help the reader distinguish igneous and volcanic units from sedimentary and other units.

\section{hachures}
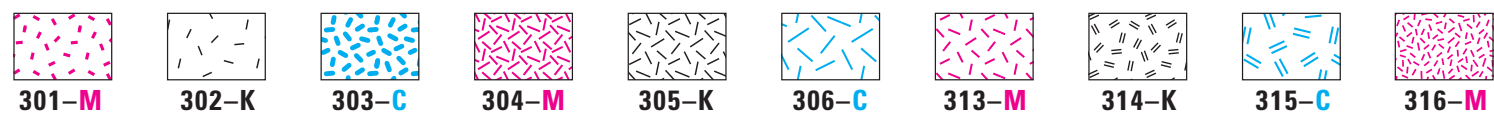

v's
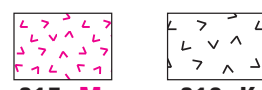

$\frac{\left.\begin{array}{l}1 \\ 1 \\ \hline\end{array}\right]}{319-C}$

317-M

318-K

+'s

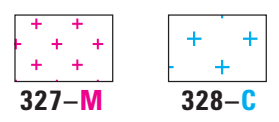

\section{Fault Zone and Ore Patterns}

Wide fault zones or large bodies of ore can be patterned with crosshatch lines, with one set of lines placed at a $45^{\circ}$ angle to horizontal. They are usually printed in black or magenta over a white or light background. The following patterns can obscure the base map and type, especially if shown in black, so they are not always used.

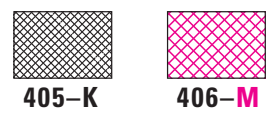


The following table shows some selected examples of background colors and colors for point patterns.

Table 3. Selected examples of background colors (CMYK codes shown below color boxes) and various point patterns (pattern numbers shown above color boxes) for geologic maps.

CMYK values: $A=8 \%, 1=13 \%, 2=20 \%, 3=30 \%, 4=40 \%, 5=50 \%, 6=60 \%, 7=70 \%, X=100 \%$.

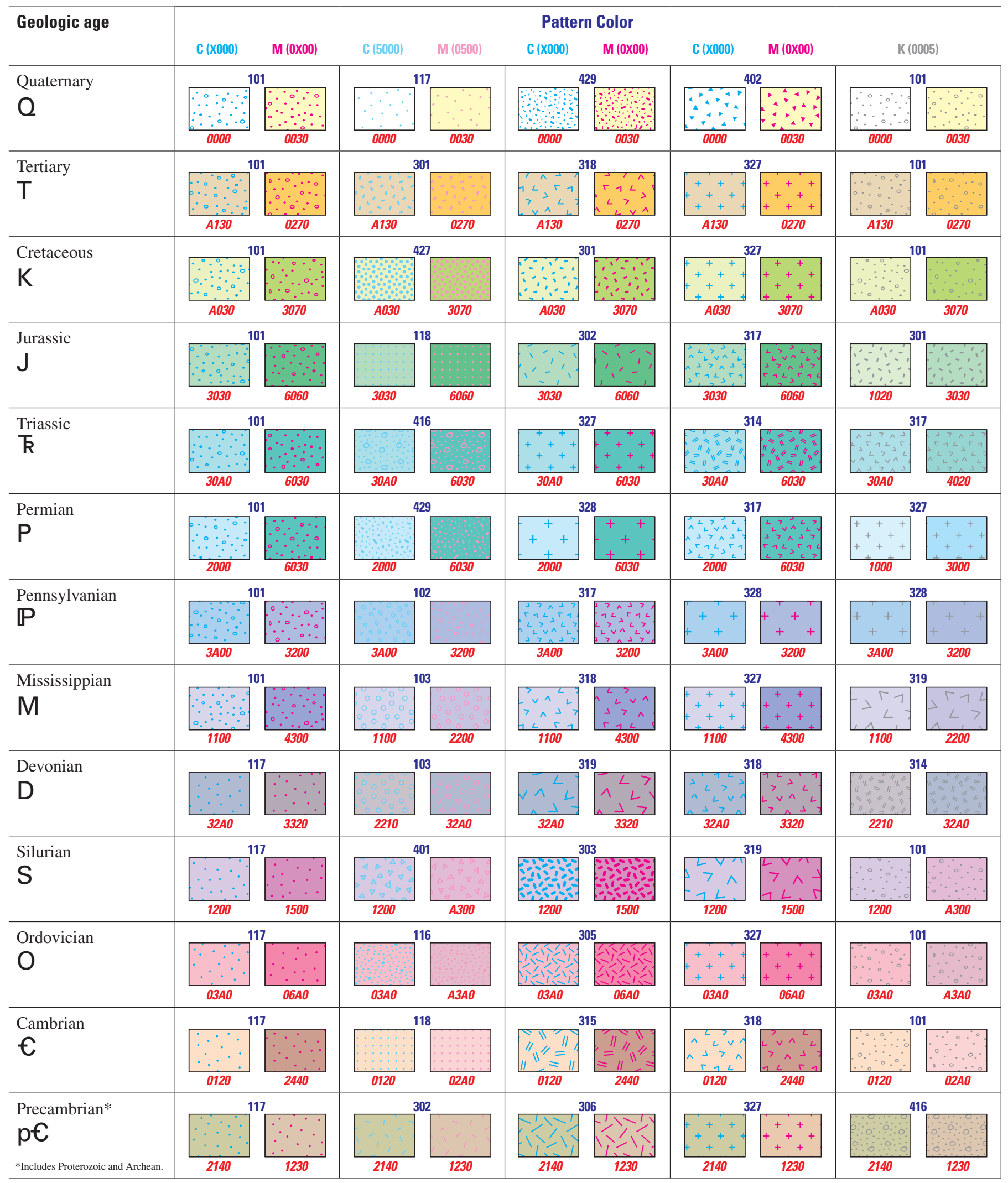


Color Standards for Line and Point Symbols and Other Map Symbols on Geologic Maps

USGS standards for line and point symbols and other map symbols are shown in USGS Open-File Report 99-430 [Public Review Draft-Digital Cartographic Standard for Geologic Map Symbolization (PostScript Implementation)], which is available online at http://pubs.usgs.gov/of/1999/of99-430/

Contained in this Open-File Report are all the geologic line and point symbols you will need. Each symbol is described, technical specifications are shown, and each symbol appears in the color in which it should be used on maps.

\section{Matching Colors and Patterns on Previously Published Maps}

In general, when we select colors for a map, we try to match colors and patterns on published geologic maps of adjacent or nearby areas, because it is helpful to users of maps to have consistent color themes on adjoining or neighboring maps in a region. However, colors and patterns on published maps could be unacceptable for use on your map for the following reasons:

They detract from the legibility and usability of your map-Some colors and patterns that work well on an adjacent geologic map may not be as legible and usable on your map.

Example 1: On a published complex color map, the same or very similar color is chosen for two different map units that are widely separated. If the same two map units are near or adjacent to each other on your map, it may be difficult or impossible to distinguish them from each other if both map units have the same or very similar colors. Two possible solutions: (1) make one of the map units match the published map, and the other a different color (still retaining the correct color for the geologic age) or (2) make the colors of both of the map units match the published map, but add a pattern to one of the units.
Example 2: Two adjoining map units on a published map cover large areas of the map, and the colors that were assigned for the two areas are very similar. (Map designers know that similar tints that cover large areas of a map are generally easy to visually distinguish.) However, if those same two adjoining map units are present on your map as extremely thin bands, the reader might have a difficult time distinguishing them from each other if their colors are very similar. Two possible solutions: (1) make one of the map units match the published map and the other a much brighter and more intense value (still retaining the correct color for the geologic age) or (2) make both of the map units match the published map and add a pattern to one of the units.

Example 3: On a published map an igneous intrusive rock is shown as very tiny map units in 100 percent magenta. The same unit is on your map but covers a third of the map area. To avoid showing such a large area of solid magenta on your map, you could instead show the unit as a light tone of 20 percent magenta.

\section{Colors and patterns do not conform to USGS con-} ventions - Some State geological surveys and other organizations produce color geologic maps that do not conform to USGS color and pattern conventions.

Colors or patterns produced on older conventionally produced maps are not easily reproduced by modern digital methods.

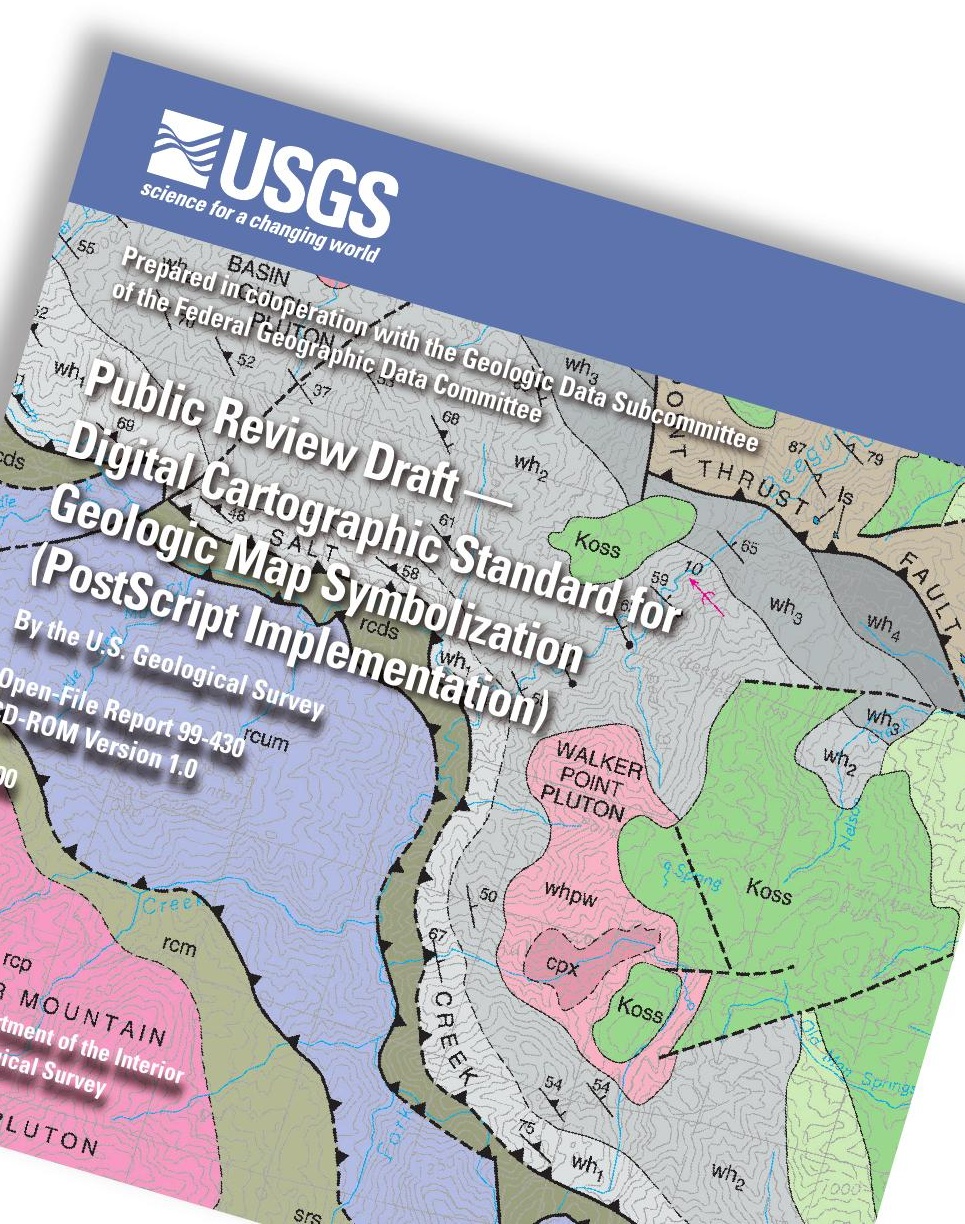




\section{Some Recommendations for Selecting Colors and Patterns}

We recommend the use of light or pastel colors as much as possible. Light colors enable easy readability of the topographic base, as well as geologic data, such as unit labels and structure symbols.

Avoid tiny map units that are too small to effectively show color and patterns on offset-printed and on-demand paper maps. If an occasional tiny map unit must be shown, be sure to label the unit so readers can identify it. However, such tiny units are perfectly fine in GIS digital databases, where such units can be enlarged on-screen as needed for viewing.

Map units that cover small areas of the map may need to have bright, intense colors so the reader can find and identify them.

Consider using light or pastel colors for map units that cover large areas of the map so that such areas won't dominate the map. The colors you pick for map units that cover large areas of the map generally determine the overall appearance of the map.

Be sure to pick colors that contrast enough with each other. However, it is easy to go overboard in selecting colors that contrast more than necessary, thus limiting the colors you have to select from.

For maps printed on an offset printing press, as a general rule, choose CMYK colors that differ by at least 20 percent, so that map colors can be easily distinguishable from each other. For example, if 20 percent magenta is chosen for one map unit, another map unit could be 40 or 50 percent magenta. Take a look at examples of printed maps to get an idea of how similar colors can be and still provide necessary color contrast.

For on-demand maps printed by computer-driven plotters, you may need to choose CMYK colors that differ by 30 percent so that map colors can be easily distinguishable from each other.

Avoid using 100 percent black as a color fill because it is opaque and will completely obscure all other colors, lines, and symbols.

Avoid mixing black with other colors to produce color fills.

Avoid dark colors composed of cyan and magenta and avoid dense black patterns; such colors and patterns can obscure numbers, symbols, and topographic contours.

The color of small polygons in areas of crowded, dense topographic contours may be unrecognizable. This can especially be a problem on reduced topographic bases. Such small polygons may need to be labeled.
On a computer-driven plotter, it is possible to print thin lines (at least as thin as 0.01 inch) composed of two or more colors. However, such thin lines may be problematic when printed on an offset printing press, due to the strong possibility of misregistration of the colors in the press. For maps that will be offset printed, we recommend that thin lines, such as contacts, faults, single-line dikes, and fold axes, as well as patterns, be shown in a single printing ink to avoid the problem of lines or patterns that have halos or fringes of unwanted colors. The halos or fringes are caused by misregistration of the different color layers during the offset printing process. For example, if you try to make a thin green line using yellow and cyan inks, the registration of the two layers (one yellow, the other cyan) that make up the line has to be perfect or the result will be a green line with a yellow and (or) cyan halo or fringe-or even worse, two lines, one yellow and one cyan. Perfect registration is extremely difficult when printing large map sheets on offset printing presses.

For offset-printed maps, make sure that thin lines and patterns overprint underlying colors. For example, if you have a thin line (the color of the line could be black, cyan, or magenta) that overlays a polygon of color, the polygon color should be continuous beneath the line; there should not be a white area under the line where the color of the polygon is blocked out. If thin lines and patterns do not overprint underlying colors, misregistration of the printing plates during printing will cause the white blocked out areas to become visible, which will detract from the appearance of the map. From Droster (2000): "Overprinting is an attribute [in Adobe Illustrator] that can be applied to the fill and/or stroke of an object or type. When "overprint" is selected, the color of the feature mixes with the color of the underlying objects. The mixing effect continues to the bottom layer unless it is interupted by a "nonoverprinted" object. Without "overprint" selected, an object "knocks out" all of the layers below it. Because the effects of overprinting are not visible until the file is color separated, it's commonly overlooked or not used."

For maps that will be printed on paper, resist the temptation to select colors on the basis of how they look on a computer monitor. Computer monitors are self-luminous (they produce RGB light). In contrast, CMYK colors on paper are produced by light from overhead lighting and (or) daylight that is absorbed and reflected to produce the colors you see. Combination colors composed of large percentages of color look beautiful and bright on a monitor because increasing the amount of color in the RGB system adds more light to the screen of your monitor. In contrast, the opposite occurs when adding more ink to paper in the CMYK system. The higher the percentages of each of the CMYK inks in a combination color, the greater the amount of light that is absorbed, resulting in less light that is reflected to the viewer. Such colors can appear dull on paper.

For maps that will be printed on an offset printing press, be aware of the effect that uncoated and coated paper stock will have on the appearance of the map. In our experience, the colors on maps printed on uncoated stock (such as E30 paper) will print somewhat darker than colors on maps printed on coated stock. 


\section{Base Maps}

Proper screening of base maps that have topographic contour lines is crucial to the usability of the base map and the overlying geologic data. For offset-printed maps, we recommend 30 percent black for most topographic bases. Occasionally, 35 or 40 percent black is needed to make the topographic contours and other base information readable. For enlarged topographic bases that have thick contour lines and thick type (or reduced bases that have crowded and congested contour lines), it is sometimes necessary to screen the base at values as low as 20 percent black for offset-printed maps. On some complex maps that are printed on offset presses, a separate brown printing ink is used for the base to improve clarity of map information.

For on-demand maps printed on ink-jet plotters, we recommend 50 or 60 percent black for most topographic bases.

Screen water features on base maps properly-rivers are shown in solid cyan; open water (lakes, reservoirs) in 20-30 percent cyan.

The topographic base map image should not have vegetation or urban tints or other tints or dense patterns. Where such tints and patterns are present on base maps, map unit colors are altered or look darker, and numbers and symbols can be hard to read.

For geologic maps that have both shaded-relief and topographic bases, proper screening of the topographic contours and numbers can be tricky. Such maps usually require topographic contours that are screened 40-50 percent black for offset printed maps. For on-demand maps, contours and numbers sometimes have to be shown as dark as 70 percent black to show through the shaded relief.

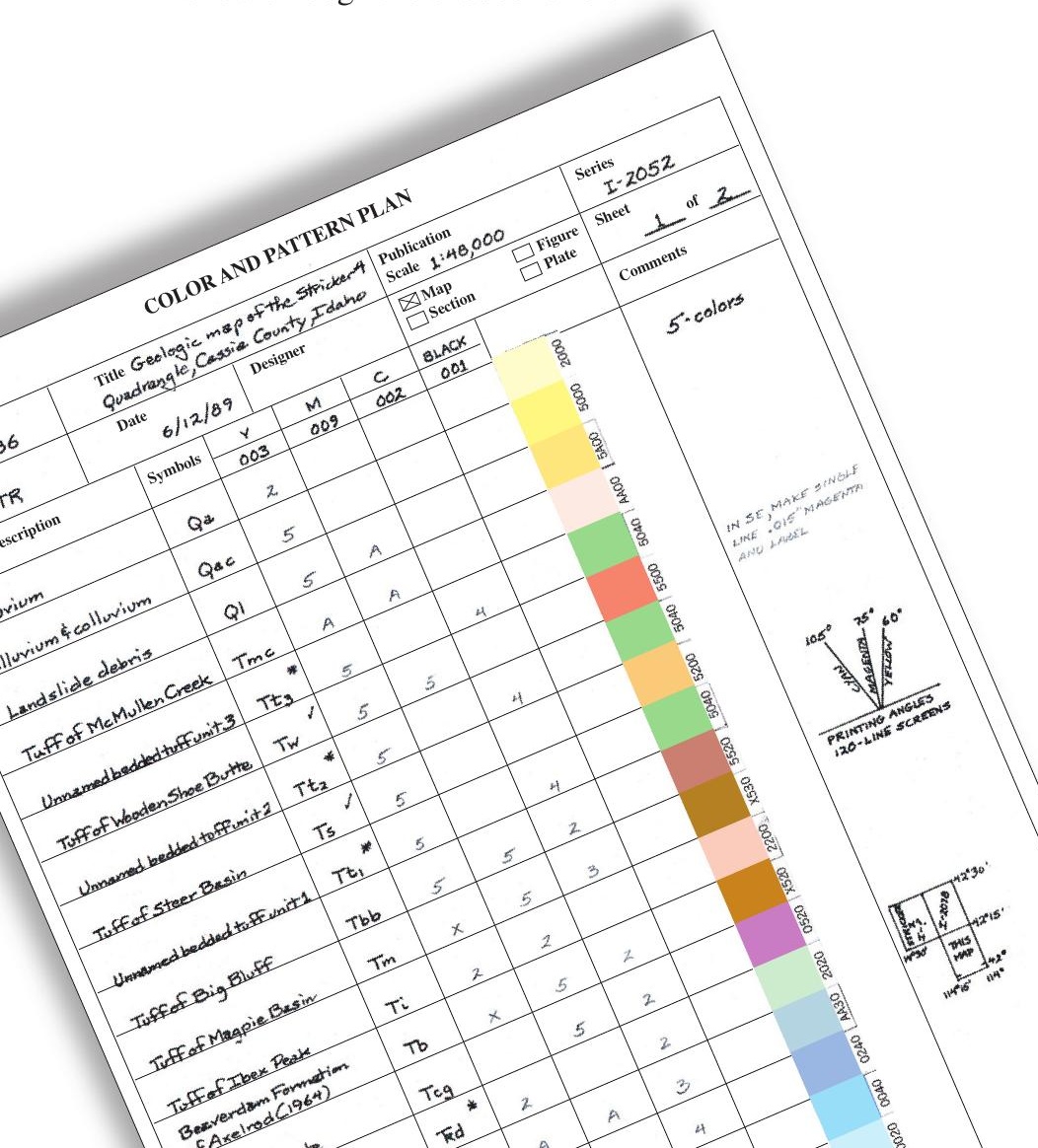

\section{Map Color Guides}

[Some map designers who use MaPublisher and (or) GIS software for selecting and viewing map units and line and point symbols on screen do not use paper color guides when they select map colors and patterns. However, map designers who do not use MaPublisher or GIS software to select and view map data on screen may need paper color guides as described in this section.]

Before you select colors for a map, you will probably need paper color guides of the map and correlation. Color guides have preliminary colors assigned to map units and symbols. Such colors are generally hastily assigned and serve only as a visual aid for making final color selections for the published map.

We recommend bright, high-contrast colors for color guides so that it will be easy to distinguish all map units from each other.

Color guides are helpful to view and study as final color selections are being made. The color guides reveal features of the map, such as map units that are numerous and cover large areas; map units that consist of only a few tiny areas; unusual shapes of map units; structural, stratigraphic, and age relationships of map units; and different kinds of line symbols and point symbols used on the map.

In addition, a copy of the description of map units and symbols is needed to refer to as colors are selected. The description of map units will provide information such as age of map units, lithology of map units, which map units are grouped together, and geographic location of tiny, hard-to-find map units.

Some very complex maps may need multiple color guides. Some complex maps will also need colored line guides and colored symbol guides, which help you see at a glance the abundance and different types of line and point symbols that will need to be color coded.

An effective job of color and pattern selection should start with the careful study of the color guides and the description of map units. Only then should the process of color selection begin.

\section{Color and Pattern Plan}

A color and pattern plan is a document that records the final color and pattern selections for a map. Once the map is published, the color and pattern plan is filed for future reference. Some designers file a digital version of the color and pattern plan. Other designers think that users can refer to the digital file of a map as the record of color and pattern selections. 


\section{Acknowledgments}

This document is a compilation of resources, techniques, and expertise dating back to the beginning of USGS geologic map making. USGS geologists and publications specialists have contributed to development of the USGS color and pattern standards over the past 100+ years. Notably, in the 1970s, the USGS Publications Division developed and printed the USGS geologic color standard as Technical Standards Paper No. 9.03.1, which has been updated for this document.

In the early 1990s, Jane Ciener devised the large color chart (plate 1) that is included with this document. The color chart was digitized by Tamara Gipprich, who also converted YMCK values to CMYK values. Doug Stoeser provided funds and the driving force for digitizing the color chart. This document was compiled and reviewed by Craig Brunstein, Alex Donatich, Diane Lane, and Carol Quesenberry. The final layout and design were done by Carol Quesenberry.

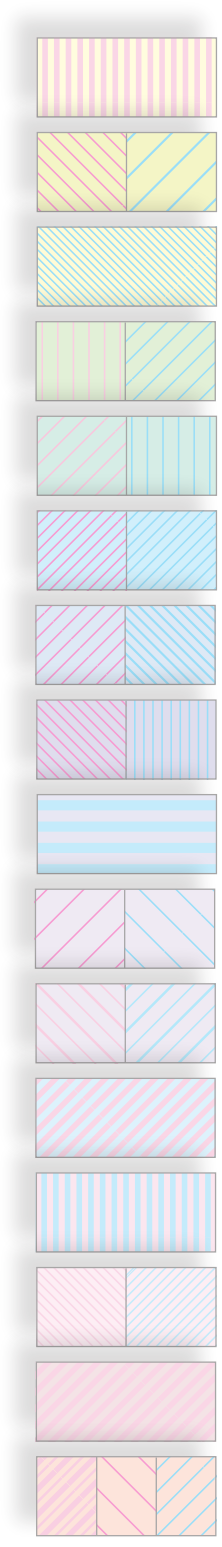

\section{Sources of Information and References}

Droster, B.R., 2000, Registry Trapping in Adobe Publishing Software, the Overprint Option: poster presentation and handout for USGS PUBS 2000 Conference, held in Denver, Colorado, in 2000. Poster and handout available online at http://capp.water.usgs.gov/pub2000/index.html

Moore, R.B., and Trusdell, F.A., 1991, Geologic map of the lower east rift zone of Kilauea volcano, Hawaii: U.S. Geological Survey Miscellaneous Investigations Series Map I-2225, scale 1:24,000.

Powell, J.W., 1890, Tenth Annual Report of the U.S. Geological Survey, p. 63-79.

U.S. Geological Survey, 1881, Second Annual Report of the United States Geological Survey, 1880-1881: U.S. Geological Survey Second Annual Report, 588 p.

U.S. Geological Survey, 1995, Cartographic and digital standard for geologic map information: U.S. Geological Survey Open-File Report 95-525.

U.S. Geological Survey (Prepared in cooperation with the Geologic Data Subcommittee of the Federal Geographic Data Committee), 1999, Public Review Draft_-Digital Cartographic Standard for Geologic Map Symbolization (PostScript Implementation): U.S. Geological Survey OpenFile Report 99-430 (Online version 1.0). Available online at http://pubs.usgs.gov/of/1999/of99-430/

U.S. Geological Survey Publications Division, various dates, Publications Division Cartographic Technical Standards: [a compilation of cartographic Technical Standards Papers dating from the 1970s to late 1980s. Includes Technical Standards Paper No. 9.03.1 about colors and patterns for geologic maps].

Willis, Bailey, 1912, Index to the Stratigraphy of North America: U.S. Geological Survey Professional Paper 71, p. 21-30.

NOTE: This book is printed on 70-pound white coated text dull finish paper. The front and back covers are printed on 80-pound white litho coated cover stock with aqueous coating. Plate 1 is printed on 60-pound white map lithograph finish (uncoated) paper.

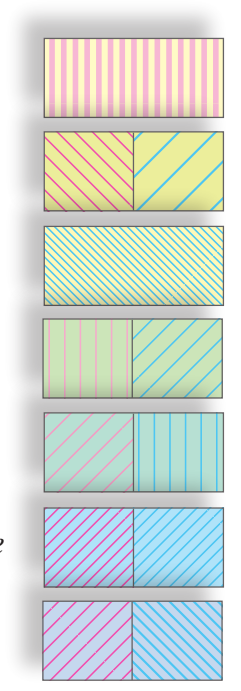


$(x)-1=1$

f 18

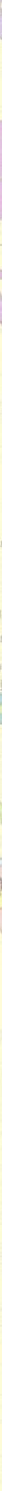

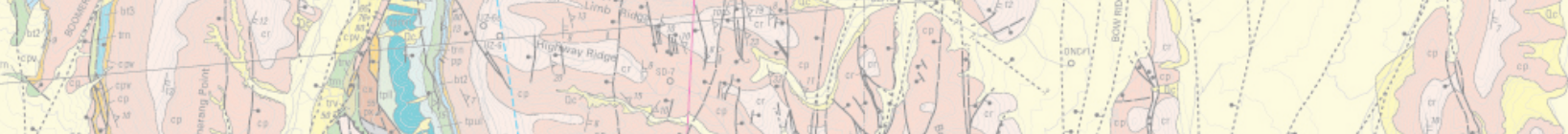

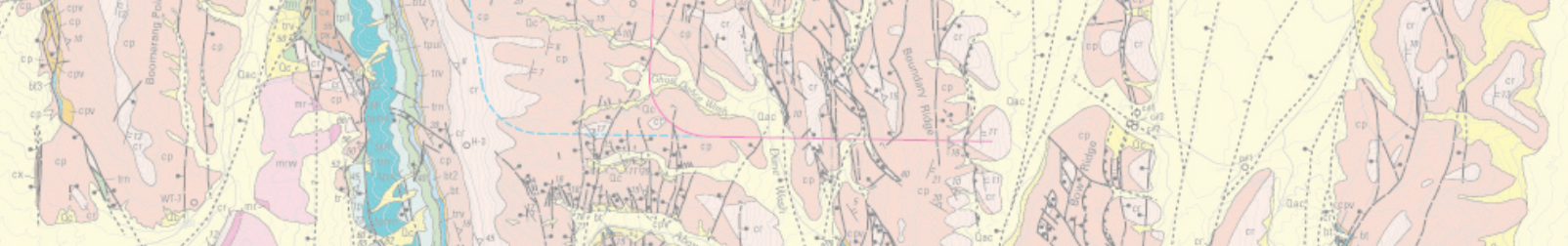

AD

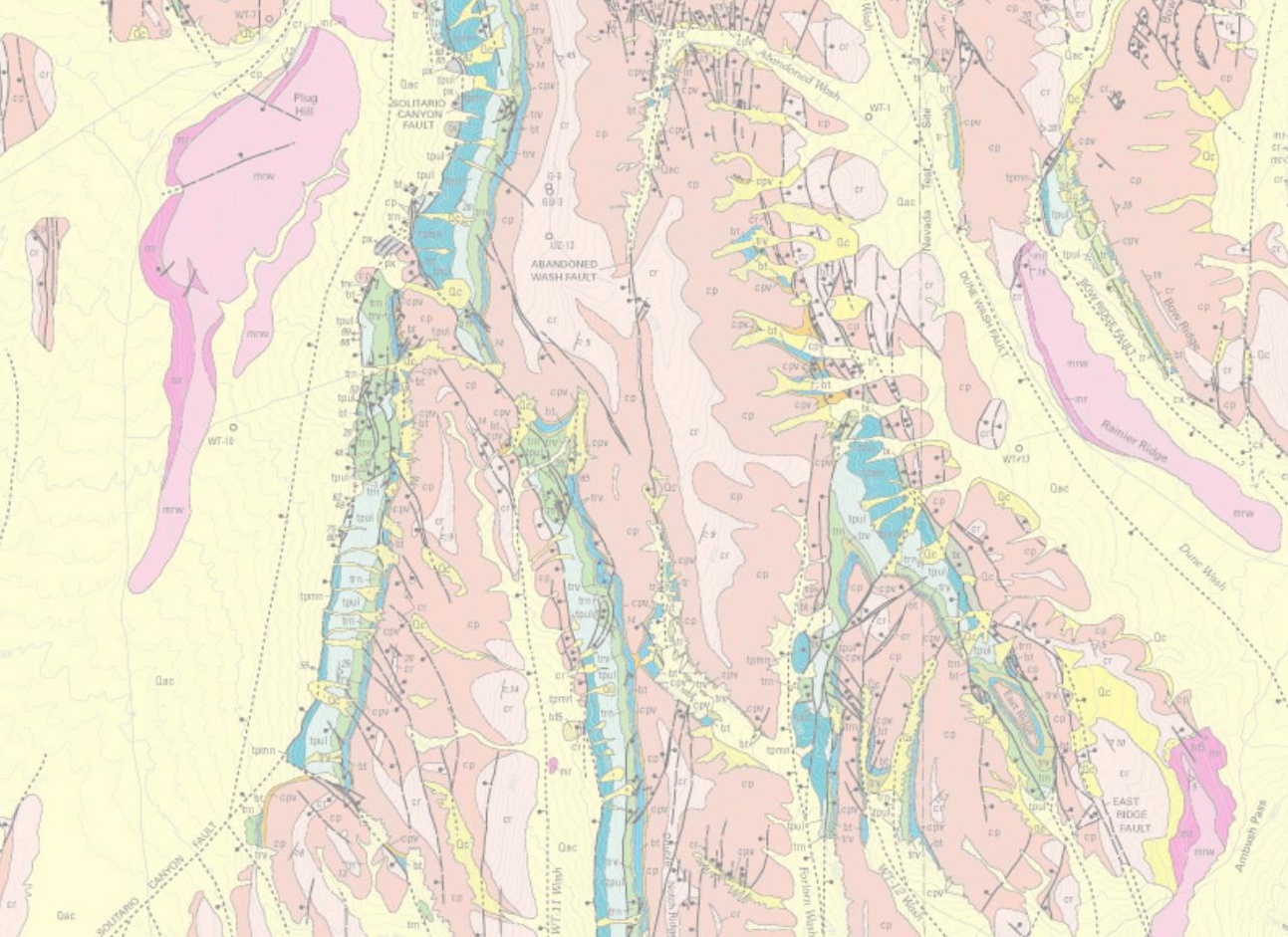

